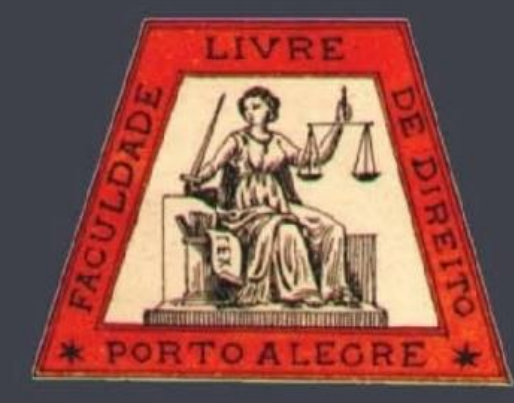

\title{
A problemática em Moçambique do rapto, morte e retirada de partes de corpo de pessoas albinas
}

The issue in Mozambique of abduction, death and removal of body parts of albinos
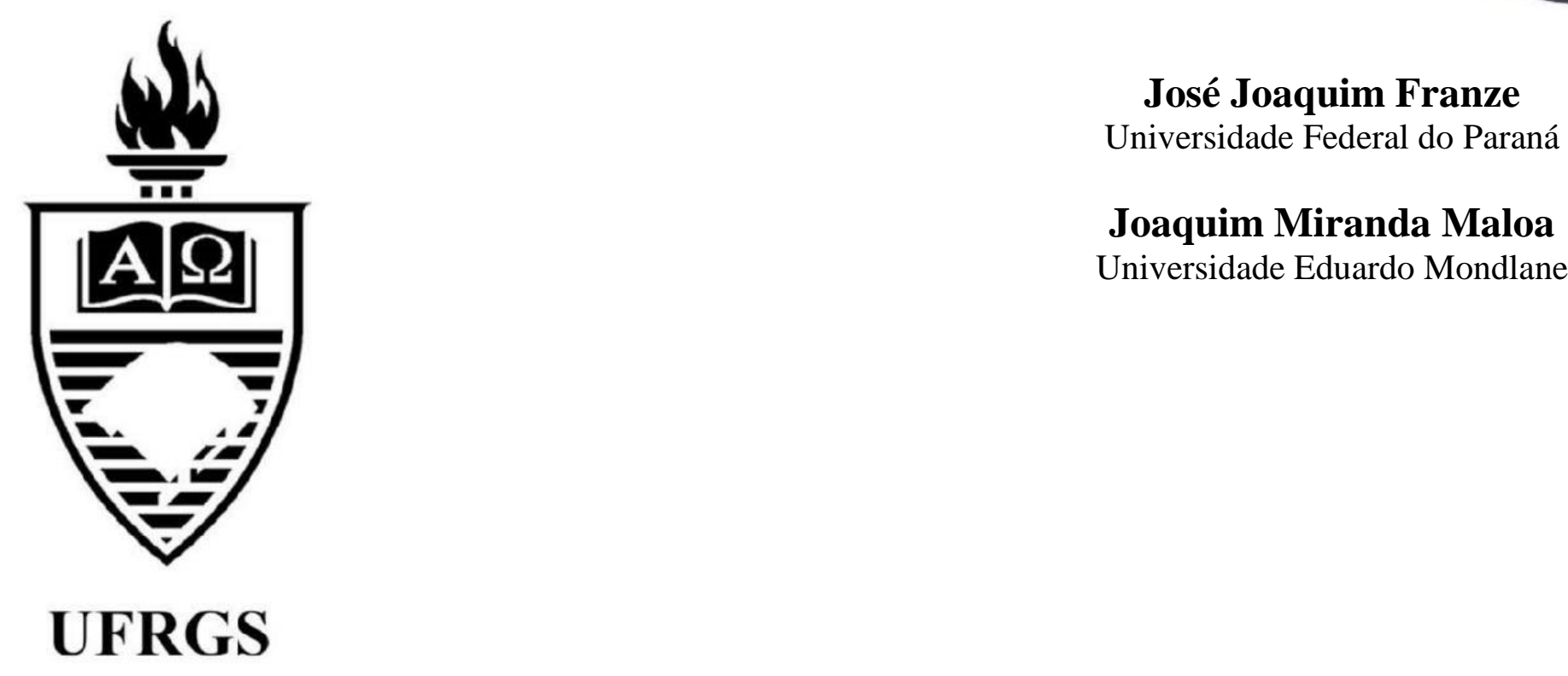

Joaquim Miranda Maloa Universidade Eduardo Mondlane 


\section{A problemática em Moçambique do rapto, morte e retirada de partes de corpo de pessoas} albinas

The issue in Mozambique of abduction, death and removal of body parts of albinos

José Joaquim Franze*

Joaquim Miranda Maloa**

\section{REFERÊNCIA}

FRANZE, José Joaquim; MALOA, Joaquim Miranda. A problemática em Moçambique de rapto, morte e retirada de partes de corpo de pessoas albinas. Revista da Faculdade de Direito da UFRGS, Porto Alegre, n. 37, p. 278-290, dez. 2017.

\section{RESUMO}

Neste artigo fazemos uma abordagem baseada em sociologia do Direito à luz das teorias da Ação Situacional e da Ecologia Humana para compreendermos a problemática em Moçambique de rapto, morte e tráfico de órgãos humanos de pessoas albinas. Também examinamos de maneira comparativa os objetivos do tráfico de órgãos humanos entre Moçambique e outros países não africanos, a fim de estabelecer parâmetros. Partimos do pressuposto que o tráfico de órgãos humanos de pessoas albinas em particular em Moçambique e no geral em África está relacionada com práticas "mágico-religiosas". Os argumentos avançados nesse texto são embasados em pesquisa qualitativa, sobretudo na revisão da literatura sobre o assunto e consulta documental.

\section{PALAVRAS-CHAVE}

Albino. Retirada de partes do corpo humano. Crime.

\begin{abstract}
In this paper we make an approach based on Sociology of Law in the light of Situational Action and Human Ecology theories to understand the issue in Mozambique of abduction, death and trafficking of human organs of albinos. We also examine in a comparative way the objectives of human organ traffic between Mozambique and other non-African countries in order to establish parameters. We assume that trafficking of human organs of albino in particular in Mozambique and in general in Africa is related to "magic-religious" practices. The arguments advocated in this text are based on qualitative research, especially in the literature review on the subject and documentary consultation.
\end{abstract}

\section{KEYWORDS}

Albino. Removal of human body parts. Crime.

\section{SUMÁRIO}

Introdução. 1. Explicando o crime de rapto, morte e tráfico de órgãos humanos de pessoas albinas em Moçambique. 2. Teorias sociológicas que possam explicar casos de venda de partes do corpo humano de albinos em Moçambique. 3. Análise comparativa do tráfico dos órgãos humanos entre Moçambique e outros países não africanos: caso particular do Brasil. Considerações finais. Referências.

\section{INTRODUÇÃO}

Neste artigo fazemos uma abordagem da sociologia do Direito, à luz das teorias da Ação Situacional e da Ecologia Humana para compreendermos a problemática em Moçambique de rapto, morte e tráfico de órgãos humanos de

\footnotetext{
${ }^{*}$ Doutorando em Sociologia (Universidade Federal do Paraná - UFPR). Mestre em Sociologia (Universidade Federal do Rio Grande do Sul - UFRGS, 2007). Mestre em Counseling (Universidade do Zimbabwe, 2012). Graduado em Ciências Policiais (Academia de Ciências Policiais - Moçambique, 2017).

** Pesquisador Associado do Centro de Análise e Políticas da Faculdade de Letras e Ciências Sociais da Universidade Eduardo Mondlane - Moçambique (CAP/FLCS-UEM). Mestre em Sociologia (Universidade de São Paulo - USP, 2012). Bacharel em Ciências Sociais (Universidade Eduardo Mondlane - Moçambique, 2005).
} 
pessoas em geral e em particular albinas ${ }^{1}$, para fins comerciais, punido com uma pena de 12-16 anos de prisão (CÓDIGO PENAL DA REPÚBLICA DE MOÇAMBIQUE, 2014). Mas também examinamos de maneira comparativa os objetivos do tráfico de órgãos humanos entre Moçambique e outros países não africanos, a fim de estabelecer parâmetros. Partimos do pressuposto que o tráfico de órgãos humanos de pessoas albinas em particular em Moçambique e no geral em África está relacionada com as práticas "mágicoreligiosas". Os argumentos avançados nesse texto são embasados, em pesquisa qualitativa, sobretudo na revisão da literatura sobre o assunto e consulta documental.

Moçambique será tomado como parâmetro comparativo e de análise da problemática situação de tráfico de órgãos humanos. O país se localiza no sudeste do Continente Africano e é banhado pelo Oceano Índico a leste e ao norte faz fronteira com a Tanzânia; a noroeste com Malawi e Zâmbia; a oeste Zimbabwe e a sudoeste com Suazilândia e África do Sul.

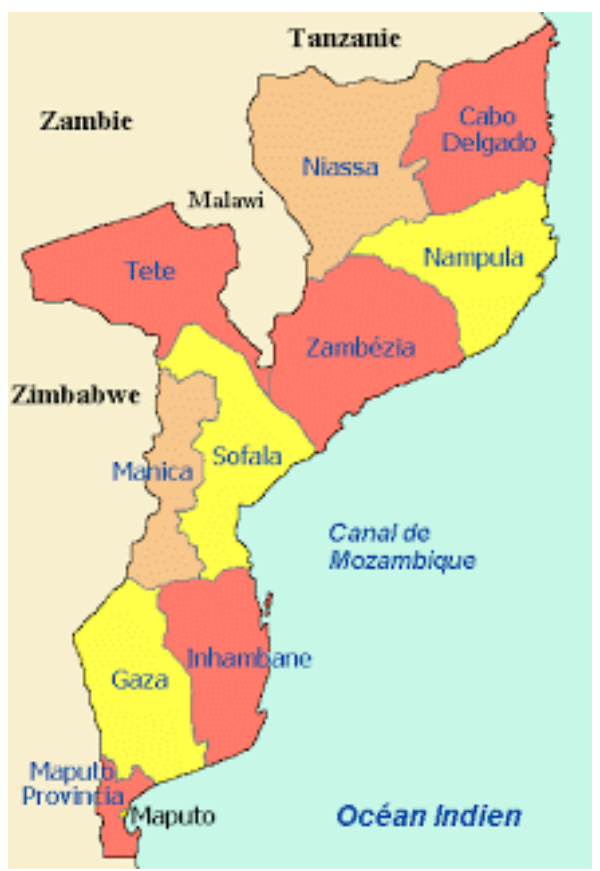

\footnotetext{
${ }^{1}$ São pessoas albinas aquelas que apresentam pigmentação do corpo, devido à fraca produção de melanina. A pigmentação do corpo pode ser total ou parcial: olhos, pele e cabelos (BORCAT; SEVERINO, 2013).
}

Figura 1 - Mapa de Moçambique (LECLERC, 2017)

Posto isso, estas ideias é que nos permitem localizar o contexto em que se recorta o nosso objeto de análise. Dividimos o artigo em três partes: Na primeira, procuramos explicar o crime de rapto, morte e tráfico de órgãos humanos de pessoas albinas em Moçambique. Na segunda, reconstruímos, sob a ótica sociológica, as teorias que possam explicar os casos de tráfico dos órgãos humanos de pessoas albinas e na terceira parte, realizamos uma análise comparativa dos tráficos dos órgãos humanos entre Moçambique e outros países não africanos.

\section{EXPLICANDO O CRIME DE RAPTO, MORTE E TRÁFICO DE ORGÃOS HUMANOS DE PESSOAS ALBINAS EM MOÇAMBIQUE}

Moçambique é privilegiado por se localizar na costa do oceano Índico e fazer fronteiras com os países africanos que frequentemente raptam, matam e traficam órgãos humanos de pessoas albinas, como por exemplo Malawi e Tanzânia ${ }^{2}$, conforme o estudo realizado em 2016 por Ikponwosa Erro, uma empresa de consultoria independente contratada por Alto Comissariado das Nações Unidas para os Direitos Humanos (ACNUDH), a fim de pesquisar os Direitos Humanos de pessoas albinas em África (ONU Brasil, 2016, online).

O país recebe forte mobilidade de pessoas e mercadorias de seus vizinhos, o que acaba por influenciar crenças comuns, como por exemplo, muitos moçambicanos, assim como: quenianos, tanzanianos, malawianos e burundeses, entre outros povos africanos aqui não mencionados acreditam que as partes do corpo de pessoas albinas, facilitam o respeito pelo medo de outrem,

${ }^{2}$ Os casos de raptos e extração de órgãos humanos em África tendem alastrar-se para os outros países da região outrora considerados acolhedores de albinos exilados, como Angola. 
elimina mortalmente os supostos "inimigos" da vida cotidiana, purifica o corpo até podem ser usadas como impedidor de ações de feitiçaria ${ }^{3}$, exercem um poder mágico para rápido enriquecimento, ascensão em cargos públicos, na carreira profissional, na vida política e sucessos nos negócios. Segundo Mariano et al. (2016), há crença nos africanos da África Austral de que as partes do corpo da população albina é portador de um "poder invisível"4, por exemplo, os dedos das mãos representam a posse e os órgãos sexuais a fertilidade (COMAROFF, 1999). Igualmente há uma crença de que as partes do corpo de pessoas albinas podem tratar casos de natureza espiritual.

Os traficantes dos órgãos humanos de pessoas albinas são na sua maioria jovens de sexo masculino ${ }^{5}$ que extraem órgãos genitais, cabelos, seios, dentes, cabeça, braços, dedos e até ossos. A título ilustrativo (ver imagem da fig. 2 adiante), em relação a esta situação, ver também os argumentos do irmão da malograda ou finada ${ }^{6}$ :

Em 2014, Lídia Pedro (albina), moçambicana, foi raptada na sua residência em Muralelo, distrito de Malema, durante a noite pelos desconhecidos. Ela foi levada junto a uma mata, onde viria a ser executada e esquartejada. Os criminosos retiraram do corpo dela: tripas, seios, dentes, cabelo, entre outras partes. No momento da ocorrência o seu marido encontrava se ausente (GASOLINA, 2015, não paginado).

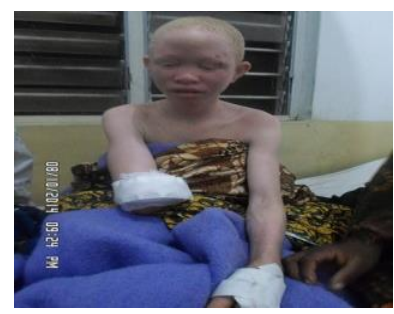

Figura 2 - Adolescente albino amputado o braço direito por malfeitores (PORTAL IG, 2015)

\footnotetext{
${ }^{3}$ Termo que significa bruxaria no Brasil.

${ }^{4}$ A crença local que considera os albinos como sendo indivíduos imortais, justificando que eles desaparecem transformando-se em outros seres vivos. São também considerados como símbolo de azar para as suas famílias e na sequência deste simbolismo, as próprias famílias têm contribuído para a sua discriminação e mortes.

${ }^{5}$ Como mostra a condenação de quatro indivíduos da cidade nortenha de Nampula a 40 anos de prisão, a saber: Atumane
}

O tráfico de órgãos humanos de pessoas albinas é motivo de apreensão por parte dos governantes, políticos, líderes comunitários, acadêmicos e a sociedade em geral, suscitando acesos debates com objetivo de encontrar melhores formas de inverter o problema. Neste cenário, convém ainda ressaltar que este fenômeno social teve a sua gênese na província nortenha de Nampula-Moçambique e pouco a pouco foi se expandindo para as províncias da Zambezia e Manica na região central e Inhambane ao Sul do país. Assim sendo, de acordo com a procuradora chefe de Nampula, em 2016, a província registrou formalmente (sem contar com casos não denunciados) 16 casos de raptos de pessoas albinas seguidos de morte e retirada de seus órgãos humanos contra $\mathbf{3 2}$ casos de igual período do ano de 2015 (LUTXEQUE, 2017).

Segundo Gasolina (2015, online), os curandeiros $^{7}$ são grandes incitadores destas práticas criminosas e gastam aproximadamente 2,5 milhões de meticais de Moçambique, correspondentes a cerca de $142.857,14^{8}$ reais brasileiros, pelo pagamento de partes do corpo de pessoas albinas, principalmente os órgãos genitais masculinos. Os curandeiros africanos chegam a gastar cerca de 75 mil dólares americanos por órgão de uma pessoa albina (MOÇAMBIQUE MEDIA ONLINE, 2016).

Em Moçambique, esta situação tem tornado cada vez mais caótica quando os pais e encarregados de educação de crianças albinas, conformados com a exclusão socioeconômica, são aliciados a entregarem os seus legítimos filhos e em contrapartida recebem valores monetários.

Abacar, suposto curandeiro e professor de madrassa de 43 anos de idade; Luís Rodrigues, comerciante de 29 anos de idade; Issa Abudala de 23 anos de idade; e Momade Oscar de 27 anos de idade (VERDADE, 2016, online).

${ }^{6}$ Maurício Carlitos Pedro, irmão da vítima.

${ }^{7}$ Nome do ao médico tradicional em Moçambique

${ }^{8}$ Calculo cambial realizado por autor tendo como base 1 Real é igual a 19 Meticais de Moçambique. 
Muitos desses casos tem sido reportado, inclusive de indivíduos que profanam túmulos de pessoas albinas enterrados para retirarem as ossadas (ver fig. 3). Um desses casos ocorreu na província de Inhambane, no sul do país:

Em outubro de 2015, a Polícia moçambicana afeta no distrito de Massinga deteve três indivíduos em flagrante na posse de ossadas humanas de um indivíduo albino. Segundo eles, pretendiam vende-las na província nortenha de Cabo Delgado. Os três indivíduos ora detidos, exerciam atividade de garimpo na província de Cabo Delegado, neste caso escalaram o distrito de Massinga (sul do país), com proposito exumar o corpo de um indivíduo albino, para se apoderar das suas ossadas, com o objetivo principal de -os vender para fins mágicos (O PAÍS, 2015).

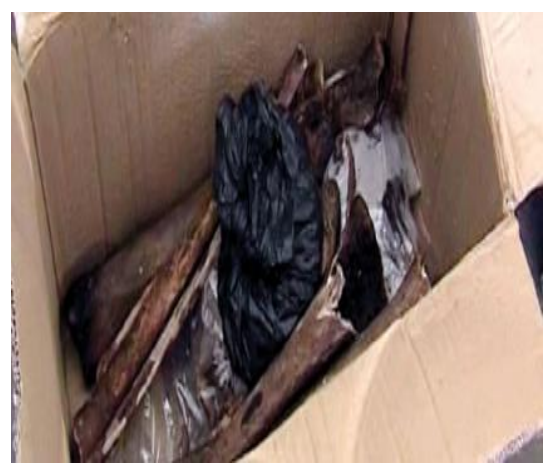

Figura 3 - Ossadas humanas de albino encontradas na posse de três indivíduos (O PAÍS, 2015)

Estas crenças começaram em Malawi e Tanzânia, tendo se difundido rapidamente para Moçambique (NOTÍCIAS, 2015, online; FELLOWS, 2009; MARIAMO et al, 2016; MELLO, 2013; GASOLINA, 2015, online). Os motivos da incidência nestes países vizinhos podem estar associados à predominância da população albina e da crença de que as partes do corpo da pessoa albina são portadoras de um "poder invisível". Mas também não podemos esquecer que o contexto social do país, apresenta um aprofundamento das desigualdades sociais abissais e exclusão socioeconômica da maioria da população. É justamente nesse processo de exclusão socioecômica e aprofundamento das desigualdades sociais que os jovens que ambicionam uma vida de luxo de forma rápida são atraídos a praticar raptos e homicídios de pessoas albinas com a intenção de vender os seus órgãos humanos para um mercado criminal já instalado, que são os curandeiros que compram e vendem como receita de riqueza aos seus utentes. Podemos afirmar que o contexto de valorização e incentivo dessas práticas por curandeiros é uma das causas de ocorrência dessa conduta declarada em leis como "crime hediondo" (CÓDIGO PENAL DA REPÚBLICA DE MOÇAMBIQUE, 2014).

Dentro deste contexto de proliferação do medo e insegurança, as pessoas albinas sentem cada vez mais discriminados pela sua condição biológica, quer em termos de aquisição de emprego, quer em termos educacionais e também em termos de exercício de seus direitos de livre circulação, tudo por temer pelo rapto. Essas práticas contrastam com a constituição da República de Moçambique, que prescreve: "Todo o cidadão tem direito à vida e à integridade física e moral e não pode ser sujeito à tortura ou tratamentos cruéis ou desumanos" e que: "Todos os cidadãos são livres de circular no interior (...) do território nacional, excepto os judicialmente privados desse direito" (CONSTITUIÇÃO DA REPÚBLICA DE MOÇAMBIQUE, 2004, p. 1217).

\section{TEORIAS SOCIOLÓGICAS QUE POSSAM EXPLICAR CASOS DE VENDA DE PARTES DO CORPO HUMANO DE ALBINOS EM MOÇAMBIQUE}

Uma das tarefas mais interessantes da sociologia é a capacidade de interpretar a sociedade. Interpretar e oferecer "explicação lógica, racional e coerente do mundo social" (RODRIGUES, 2014, p. 9). Neste texto vamos basear a nossa interpretação em duas teorias básicas: a Teoria da Ação Situacional, conhecida 
em inglês por sigla SAT e Ecologia Humana ${ }^{9}$, ambos são formas de discursos interpretativos e nessa medida produzem realidades. A diferença entre elas está em suas qualidades operacionais. Queremos deixar claro que essas teorias serão apresentadas de forma resumida e não são as únicas teorias que possam explicar os fatos, mas pensamos que elas possam fornecer instrumentos necessários para a compreensão e interpretação dos casos de tráfico dos órgãos humanos de pessoas albinas em Moçambique.

Para a Teoria da Ação Situacional (SAT), os crimes são ações morais guiadas por regras sobre o que é bom ou mau. Segundo o professor Per-Olof H. Wikström (2014), as ações morais nos dizem as coisas erradas que devemos fazer ou não podemos fazer. Os crimes são atos que quebram regras de condutas declaradas em leis. A teoria propõe ainda que os seres humanos são fundamentalmente atores guiados por regras e que suas respostas aos motivos para o crime são essencialmente um resultado da interação entre suas propensões morais e o contexto (WIKSTRÖM, 2014). Para este autor explicar o crime (ou tipos particulares de crime) é explicar por que os indivíduos seguem e quebram as regras de condutas declaradas em leis. Para esta teoria as pessoas cometem o crime por causa dos ambientes situacionais em que elas participam (WIKSTRÖM, 2014). Assim, Wikström; Treiber (2009), encara o crime como estudo na área geográfica de Chicago e analisando uma ocorrência ecológica, tendo o seu foco cientificamente a problemática da delinquência, principal a interação entre o indivíduo e o concluiu que a delinquência era causada pela ambiente - isto é, a probabilidade que cada desorganização social movida pelo total indivíduo apresenta de agir conforme um dado afrouxamento das relações entre as instituições modo quando é exposto a um conjunto de formais e informais de controle social. Como condições ambientais. As condições ambientais sabemos, a sociedade urbana moçambicana pósafetam não somente o custo moral, mas também o década de 1990, passou por uma acentuada custo de oportunidade (SHAW, 1972; OLIVEIRA, "erosão das regras sociais", instigada por 2009).

Enquanto a Ecologia Humana surge das realidade bem próxima da captada por Florian ciências naturais referindo ao estudo de Znanieck e William I. Thomas ao estudar as ajustamento de plantas e seres animais ao seu meio

\footnotetext{
${ }^{9}$ Este termo será explicado mais adiante.
} 
transformações das cidades americanas na década de 1920 (FREITAS, 2004).

Giddens apud Oliveira (2006), tem razão ao indicar que a modernidade associada ao nosso tempo traz consigo descontextualização dos sistemas sociais, ou seja, cria à desinserção das relações sociais dos contextos locais de interação e a sua reestruturação através de extensões implícitas de espaço-tempo, engendrada pelo processo de globalização. A descontextualização das relações sociais, resulta da desconformidade de distintas culturas no mesmo meio social (GIDDENS apud OLIVEIRA, 2006), para o caso moçambicano, essa realidade deu-se com o processo de migração interna dos moçambicanos e imigração dos estrangeiros, que tinha como foco as cidades moçambicanas. Como dito acima, moçambicanos assim como os seus vizinhos de países mais afetados por esta modalidade criminal, nomeadamente Malawi e Tanzânia, estão em constante troca de conhecimentos, crenças em relação a vida e mesmo em questões de matérias de sobrevivência e existência. Tais situações provocam mudanças nos valores morais da sociedade moçambicana e promove também um "hibridismo cultural" e ruptura dos "mecanismos tradicionais de controle social" (família, vizinhança, religião, escola). Hoje em dia observase trocas constantes de vizinhanças, motivados por baixo preço do solo urbano e arrendamento de casas que acaba por afetar o controle social dos bairros, permitindo a ocorrência de casos de raptos, mortes e retirada de partes do corpo de pessoas albinas. Esta realidade foi bem testada por Wirth apud Pierson (1970), ao estudar a comunidade urbana americana em transformação entre as décadas de 1920-1940, que nas cidades um grande número de pessoas mora muito próximo um do outro, sem que se conheçam pessoalmente produzindo assim comportamentos desviantes incluindo a criminalidade.
3 ANÁLISE COMPARATIVA DO TRÁFICO DOS ÓRGÃOS HUMANOS ENTRE MOÇAMBIQUE E OUTROS PAÍSES NÃO AFRICANOS: CASO PARTICULAR DO BRASIL

O progresso da ciência medicinal no que concerne ao transplante de partes do corpo na atualidade, torna este problema social praticável, devido à crescente procura por esses órgãos humanos, por parte de diversos pacientes que desesperadamente esperam por estes bens vitais. Por falta destes órgãos em pessoas mortas, devido a elevada demanda, muitas vezes se constrói um "mercado subterrâneo" e ilícito dos órgãos humanos, caso não haja voluntários na doação destes órgãos, estimulando indivíduos a procurar formas de assassinar outrem para em seguida retirar os órgãos humanos como forma de ganhar dinheiro de maneira fácil e rápida (UNIÃO EUROPEIA, 2016).

Como sabemos, a venda de órgão humanos é uma questão ética e moral, por isso esta prática fica inteiramente protegida não pela sua invisibilidade, mas sim pelo perfil das vítimas assassinadas que muitas das vezes são indivíduos de classe social baixa, sem família com poderes de fazer uma queixa consistente ou procurar o corpo dos seus entes queridos. Segundo Gauer et al (2003, p. 22), o tráfico de órgãos humanos representa a terceira atividade ilegal mais lucrativa do planeta, rendendo aos seus praticantes cerca de 7 a 13 bilhões de dólares a cada ano no planeta, seguido do tráfico de armas e de drogas.

Segundo Mariamo (2003), a Índia constitui o país mais privilegiado para o tráfico internacional de rins de maneira ilegal e são extraídos e comprados de doadores vivos. Para Scheper-Huges (2003), diversos pacientes dirigem-se junto a países onde órgãos humanos são obtidos através do processo de compra e venda. Neste contexto, a África do Sul tem sido considerada como um país de "turismo de 
transplantes". Olhando para o caso brasileiro, as fontes salientam que os residentes das favelas, principalmente do Recife (Estado de Pernambuco), no Brasil, têm sido recrutados para se deslocarem até Durban, na África do Sul, onde são submetidos a várias cirurgias para a extração de um rim a ser transplantado em pacientes ricos vindos de Israel em troca de valores pecuniários. Os estudos indicam que alguns indivíduos vendem seus rins devido a extrema pobreza e exclusão socioeconômica, muitas vezes sem conhecimento de que essa prática compromete a sua saúde no decorrer do tempo por causa do analfabetismo (SCHEPER-HUGES, 2003).

O tráfico de partes do corpo humano revela uma forma de poder na qual se privilegia a vulnerabilidade social de vítimas como alternativa mais viável para convencê-las, alegadamente para saírem da sua situação de pobreza, recebendo como contrapartida dinheiro e outros benefícios, como oferta de cesta básica durante um período de tempo ou mesmo emprego, obtendo desta forma anuência "tipicamente forçosa" das suas vítimas. Os traficantes fazem de tudo quanto dispõem para que as suas vítimas estejam sob sua dependência total, mantendo tudo em absoluto sigilo (MONTEIRO; OSORIO, 2009).

De acordo com Fellows (2009), a venda de órgãos humanos está ligada ao mercado internacional dos órgãos humanos, consistindo no seu transporte, quer dentro, quer fora das fronteiras nacionais com propósitos meramente comerciais. Os estudos da União Europeia sobre tráfico de órgãos humanos (UNIÃO EUROPEIA, 2016), a venda de órgãos humanos consiste em práticas ilícitas de comercialização de órgãos e tecidos humanos para objetivos de transplante. Esta atividade comercial de órgãos humanos, tem um caráter fortemente sofisticado e enraizado, caraterizado pela forte invisibilidade dos seus mandantes e por um sigilo fortemente estruturado, com objetivos de escapar qualquer indício em caso de suspeita policial ou de outros órgãos de administração da justiça. Igualmente a UNESCO (2006), aponta que os praticantes, pelo seu alto grau de crueldade, dificultam a denúncia de qualquer indivíduo interessado em desmascarar essas práticas, temendo por uma retaliação fatal. A maioria dos mandantes destas práticas delitivas é constituída por indivíduos que detém forte poder econômico e de alta capacidade de influenciar o poder das instituições de administração da justiça.

Conforme Lombard (2013), contrariamente do que acontece na Europa, Brasil, China e Índia, onde o tráfico dos órgãos humanos tem como finalidade cirúrgica de transplante. Na África esses órgãos ou partes do corpo humano tem como finalidade satisfazer as crenças "mágicoreligiosas" (RAPOIO, 2014). A título de exemplo, tivemos casos recentes no país de pessoas com calvície que tiveram cortadas as suas cabeças com a crença de que na sua careca existia ouro:

A perseguição e assassinato de indivíduos calvos para a extracção e venda dos seus órgãos, no distrito de Morrumbala, província da Zambézia, para presumíveis rituais supersticiosos, tem motivações culturais e é encomendada pelos médicos tradicionais, considera a Polícia da República de Moçambique (PRM), que indica, também, existir uma crença segundo a qual as vítimas têm, na cabeça, algum poder que gera fortuna. Nos últimos dias $[\ldots]$ três homens com problemas de calvície foram mortos [...]. A Polícia moçambicana deteve pelo menos dois cidadãos [...] alegadamente por terem sido surpreendidos por populares num cemitério na posse de uma cabeça humana com calvície. Porém [...]. O que é certo $[\ldots]$ acredita-se que "indivíduos carecas têm um suposto poder" de enriquecimento e tal capacidade "pode ser transferida", pelos curandeiros, para uma outra pessoa de modo a enriquecer, também. "É um pensamento bastante errado" (SAMBO, 2017).

\section{CONSIDERAÇÕES FINAIS}

Os resultados da pesquisa revelaram que os motivos da incidência de rapto, morte e retirada de órgãos de pessoas albinas em Moçambique, não tem apenas haver com a predominância dessa população, mas pelo contexto que o país atravessa, associado ao aprofundamento das desigualdades 
sociais e da exclusão socioeconômica, que atraí não morrem ${ }^{10}$, só desaparecem e transformam-se muitos curandeiros e jovens desfavorecidos a em outros seres vivos. Talvez é aí onde esconde os enveredar por aquele tipo de crime para sua homicídios da população albina durante muitas sobrevivência, dado que o mercado de tráfico de décadas para fins "mágicas-religiosas". As pessoas órgãos de pessoas albinas, tornou-se atrativo e albinas foram e são durante muito tempo mais rentável. O preço das ossadas humanas e dos estigmatizados dentro das sociedades africanas em órgãos de pessoas albinas são estimados em altos geral. Os seus direitos como seres humanos valores monetários. É aí que podemos falar de uma sempre foram violados. Esquecem que as pessoas ação situacional e ecológica ao mesmo tempo.

albinas são seres humanos como qualquer um e

Para terminar, gostaríamos de fechar este merecem dignidade humana e respeito pelos seus artigo, com uma crença muito difundida na direitos fundamentais consagrados nas sociedade moçambicana de que as pessoas albinas constituições e convenções internacionais.

\section{REFERÊNCIAS}

ÁVILA et al. Comércio de Órgãos Humanos: até onde vai a autonomia do indivíduo? Porto Alegre: CAPES, $2008 . \quad$ Disponível em: <https://www.google.com.br/searcvai+a+autonomia+do+indiv\%C3\%ADduo\&gs_l=serp..jJSTPCm6 NXg>. Acesso em: 23 abr. 2017.

BORCAT, J; SEVERINO, L. As pessoas com albinismo e o novo conceito de deficiência sob o enfoque do princípio da igualdade à luz do Direito a diferença. 2012. Disponível em: <http://www.publicadireito.com.br/artigos/?cod=01cbec0730184650>. Acesso em: 06 dez. 2017.

CAMPOS, Amanda. Albinos são vendidos por até R \$ 160 mil para rituais de magia na Tanzânia. Portal $i G$, São Paulo, 12 fev. 2015. Disponível em: <http://ultimosegundo.ig.com.br/mundo/2015-0212/albinos-sao-vendidos-por-ate-r-160-mil-para-rituais-de-magia-na-tanzania.html>. Acesso em: 30 dez. 2017.

CÓDIGO PENAL DA REPÚBLICA DE MOÇAMBIQUE. Lei $n^{o}$ 35/2014. Boletim da República. I Série, n. 105, $31 \mathrm{dez} 2014$.

COMAROFF, J. Occult Economies and the Violence of Abstraction: notes from the South African Postcolony. American Ethnologist, v. 26, n. 02, p. 279-303, mai. 1999.

CONSTITUIÇÃO DA REPÚBLICA DE MOÇAMBIQUE (2004). Maputo: Imprensa Nacional.

DIAS, J. Figueredo et al. Criminologia, o homem delinquente e a sociedade criminógena. Portugal: Coimbra, 1997.

GARRAFA, Volnei; SCHRAMM, Fermin Roland. Comercialização de órgãos. In: $10^{\circ}$ CONGRESSO BRASILEIRO DE SAÚDE COLETIVA, 10., 2012, Porto Alegre. Anais... [S. 1.: s. n.], 2012.

\footnotetext{
${ }^{9}$ Mesmo perdendo a vida, a falsa crença é de que ele não morreu, mas sim transformou-se e que no seu funeral não se deve chorar.
} 
GASOLINA, Leonardo. Albinos vivem em pânico em Nampula, curandeiros pagam mais de 25 milhões de meticais pelos órgãos. Verdade, Moçambique, 19 out. 2015. Disponível em: $<$ http://www.verdade.co.mz/tema-de-fundo/35-themadefundo/55380-albinos-vivem-em-panico-emnampula-curandeiros-pagam-mais-de-25-milhoes-de-meticais-pelos-orgaos-deles>. Acesso em: 07 abr. 2017. Não paginado.

INSTITUTO NACIONAL DE ESTATÍSTICA. Projecções anuais da população total, urbana e rural, dos distritos da província de Nampula (2007-2040). Maputo: Editora do INE, 2012.

FELLOWS, S. Tráfico de partes de corpo em Moçambique e na África do Sul. Liga Moçambicana dos Direitos Humanos. [S. 1.: s. n.], 2009.

FREITA, W. C. de. Espaço urbano e criminalidade: lições da Escola de Chicago. São Paulo: Método, 2004.

KOLNSBERG, Heather R. An Economic Study: Should We Sell Human Organs? International Journal of Social Economics, v. 10, n. 30, p. 1049-1069, 2003.

LECLERC, Jacques. Le Mozambique: provinces administratives. L'aménagement linguistique dans le monde. 2017. Disponível em: <http://www.axl.cefan.ulaval.ca/afrique/mozambique-map.htm>. Acesso em: 30 dez. 2017.

LOMBARD, L. Missing Pieces: Africa's genital-stealing crime wave hits the countryside. Pacific Standard, Santa Barbara (Califórnia), 06 mar. 2013. Disponível em: <https://psmag.com/socialjustice/genital-theft-africa-central-african-republic-53341>. Acesso em: 30 dez. 2017.

LUTXEQUE, Sitoi. Albinos vivem com medo em Nampula. Deutsche Welle África, Nampula, 09 fev. 2017. Disponível em: <http://p.dw.com/p/2XGdx>. Acesso em: 26 abr. 2017.

MARIAMO, E. et al. Estudo Sobre o Tráfico de órgãos e partes do corpo humano na região sul de Moçambique. Maputo: Interact Moçambique, 2016.

MELLO, Patricia Campos. Albinos são alvos de mutilação e assassinatos em países africanos. Folha de São Paulo, São Paulo, 13 out. 2013. Disponível em: $<$ http://www1.folha.uol.com.br/mundo/2013/10/1355974-albinos-sao-alvo-de-mutilacoes-eassassinatos-em-paises-africanos.shtml>. Acesso em: 12 ago. 2017.

MOÇAMBIQUE MEDIA ONLINE. Nampula: albinos vivem com medo. Moçambique Media Online Notícias, Moçambique, 14 jun. 2016. Disponível em: <https://noticias.mmo.co.mz/2017/02/nampulaalbinos-ainda-vivem-com-medo.html\#ixzz4c54PqfsD>. Acesso em: 27 abr. 2017.

MONTEIRO, C.; Osório, C. Tráfico de Mulheres e crianças. Maputo: WLSA Moçambique, 2009.

NOTíCIAS. Caça a albinos tem epicentro na Tanzânia diz Carlos Serra. [S. 1.], 25 nov. 2015. Disponível em: <http://www.miramar.co.mz/Noticias/Caca-aos-albinos-tem-epicentro-na-Tanzaniadiz-Carlos-Serra>. Acesso em: 18 ago. 2017.

OLIVEIRA, I. et al. Reflexões sobre justiça e violência: o atendimento de vítimas de crimes fatais. São Paulo: Educ/Imprensa Oficial, 2008. 
ONU BRASIL. Pessoas com albinismo são perseguidos e mortos por praticantes de "bruxaria", destaca relatora da ONU. [S. 1.], 31 mar. 2016. Disponível em: <https://nacoesunidas.org/pessoascom-albinismo-sao-perseguidas-e-mortas-por-praticantes-de-bruxaria-relatora-onu/>. Acesso em: 12 ago. 2017.

O PAÍS. Três indivíduos surpreendidos na posse de ossada humana. Maputo, 30 out. 2015. Disponível em: <http://opais.sapo.mz/index.php/sociedade/45-sociedade/38265-tres-individuos-surpreendidosna-posse-de-ossada-humana.html>. Acesso em: 27 abr. 2017.

PARK, Robert E. Human Ecology. American Journal of Sociology, v. 42, n. 01, p. 1-15, jul. 1936.

PIERSON, Donald (Org.). Estudos de Ecologia Humana. Leituras de Sociologia e Antropologia. 2 tomos. 2. ed. rev. São Paulo: Martins, 1970.

SAVE THE CHILDREN. The Internal Trafficking and Exploitation of Women and Children in Mozambique. Save the Children Mozambique, [s. 1.], 2009.

SCHEPER-HUGHES, Nancy. Rotten Trade: Millenial Capitalism, Human Values and Global Justice in Organs Trafficking. Journal of Human Rights, v. 02, n. 02, edição especial (Human Frailty), New York, Routledge, jun. 2003..

RAPOIO, Ilda. $O$ crime de tráfico de pessoas no ordenamento jurídico moçambicano. O problema do tráfico para fins supersticiosos. Monografia (Licenciatura em Direito) - Universidade Católica de Moçambique, Moçambique, 2014.

RODRIGUES, Herbert. A pedofilia e suas narrativas: uma genealogia do processo da criminalização da pedofilia no Brasil. Tese (Doutorado em Sociologia) - Universidade de São Paulo, São Paulo, 2014.

SAMBO, Ernildo. PRM acredita no envolvimento de curandeiros na morte de homens calvos na Zambézia. Verdade, Moçambique, 08 jun. 2017. Disponível em: $<$ http://www.verdade.co.mz/nacional/62418-prm-acredita-no-envolvimento-de-curandeiros-namorte-de-homens-calvos-na-zambezia>. Acesso em: 07 dez. 2017.

UNESCO. Tráfico de pessoas em Moçambique: causas principais e recomendações. Documento de orientação (Policy Paper) n. 14.1 (P). Série de relatórios sobre a pobreza. Paris: [s. n.], 2006.

UNIÃO EUROPEIA. Relatório sobre a luta contra o tráfico de seres humanos no contexto das relações externas da União Europeia. Bruxelas: [s. n.], 13 jun. 2016. Disponível em: <http://www.europarl.europa.eu/sides/getDoc.do?pubRef=-//EP//TEXT+REPORT+A8-20160205+0+DOC+XML+V0//PT>. Acesso em: 07 dez. 2017.

VERDADE. Juiz Dimas Morroa foi implacável e sentenciou 40 anos de cadeia contra os assassinos de um cidadão albino em Nampula. Verdade, Moçambique, 19 mar. 2016. Disponível em: $<$ http://www.verdade.co.mz/destaques/democracia/57979-juiz-dimas-morroa-foi-implacavel-esentenciou-40-anos-de-cadeia-contra-os-assassinos-de-um-cidadao-albino-em-nampula>. Acesso em: 12 out. 2017.

WIKSTRÖM, Per-Olof H.; TREIBER, Kyle. Violence as Situatuinal Action. International Journal of Conflict and Violence, v. 03, n. 01, p. 75-96, 2009. 
WIKSTRÖM, Per-Olof H. Why crime happens: a situational action theory. In: MANZO, G. (Ed.). Analytical Sociology: actions and networks. Chichester: John Wiley \& Sons, 2014. cap. 03.

Recebido em: $21 / 10 / 2017$

Aceito em: 10/12/2017 
A problemática em Moçambique de rapto, morte e retirada de partes de corpo de pessoas albinas Revista da Faculdade de Direito da UFRGS, Porto Alegre, n. 37, p. 278-290, dez. 2017. ISSN: 0104-6594 Site http://seer.ufrgs.br/revfacdir Email: revistafacdir@ufrgs.br 